José L. Peñalvo

Anu Hopia

Herman Adlercreutz

\section{Effect of sesamin on serum cholesterol and triglycerides levels in LDL receptor-deficient mice}

Received: 7 January 2006

Accepted: 24 August 2006

Published online: 12 October 2006

J.L. Peñalvo $\cdot H$. Adlercreutz

Institute for Preventive Medicine

Nutrition and Cancer

Folkhälsan Research Center and Division

of Clinical Chemistry

University of Helsinki, Finland

J.L. Peñalvo ( $\square)$ (current address)

Tel.: +34-62/9046-979

Fax: +34-91/5335-484

E-Mail: penalvo@farm.ucm.es

A. Hopia

Raisio Benecol Ltd.

Raisio, Finland
Abstract Background Sesamin, a major lignan from sesame seeds has been associated with cholesterol reduction in previous reports, but recent studies suggested differences in the response to sesamin intake depending on the model studied as well as the nature of the sesamin preparation used. Aim The effect of pure sesamin epimer on serum lipids was studied in hypercholesterolemic LDL receptor-knockout mice under cholesterol fed condition. Design Animals were randomly assigned to 4 groups, fed an atherogenic diet containing stanol ester, sesamin, combination of stanol ester and sesamin or a control diet with no additions. Results The control group showed an almost 3-fold increase in serum cholesterol levels due to the atherogenic diet but no effect was seen for triglyceride levels. Stanol ester alone or together with sesamin significantly attenuated the elevation of the cholesterol levels. Conclusion Sesamin alone did not affect the elevation of the diet-induced cholesterol level and it did not enhance the effect of stanol ester.

Key words cholesterol triglycerides - lignans sesamin - enterolignans stanol ester

\section{Introduction}

The research on natural substances affecting cholesterol metabolism for prevention of hypercholesterolemic atherosclerosis has particular therapeutic importance. In particular, the identification of dietary components that can be added to foods to lower or regulate cholesterol levels has gained special interest.

Sesame seeds in general and its major lignan sesamin in particular, have been associated with various biochemical actions, mainly related to lipid metabolism, including a hypocholesterolemic effect in both human and animal-based trials (see $[1,2]$ for review). Although the general hypolipidemic effect of dietary sesamin seems to be clear in studies with rats, recent studies pointed out discrepancies in the response to sesamin between animal species [3] raising doubts about a possible extrapolation of these results to humans. Additionally, the heterogeneous nature of the sesamin preparations used in the different studies seems to be another point to consider, since different biological actions and mechanisms have been proposed for the two epimers of dietary sesamin [4]. In this study, we aimed to further investigate the hypocholesterolemic action of sesamin minimizing the above described variables and using only pure sesamin epimer and selecting low density lipoprotein (LDL) receptor-deficient mice as experimental animals. This model aims to reproduce homozygous familial hypercholesterolemia and it is characterized by decreased removal of cholesterol from the circulation due the lack of functional LDL receptors [5] that leads to increased serum cholesterol levels. 


\section{Materials and methods}

\section{Animal model}

Female ldlr-/- mice (strain number, B6.129S7Ldlrtm1Her) quality SPF were obtained from the Jackson Laboratory (Bar Harbor, Maine, US), and maintained at the Central Animal Laboratory of Raisio Benecol Ltd. (Raisio, Finland) in accordance with European guidelines (European Treaty Series No. 123, EU No 609/86, Official Journal of the European Communities No. L 358) approved by the Animal Care and Use Committee of the University of Turku (Finland) approval number 1263/02. Animals were 17-18 weeks at the beginning of the study/15-20 g and after 4 weeks of acclimatization, mice were housed (Polycarbonate Macrolon III, Scanbur AS, Denmark) in groups of $1-2 /$ cage and randomly given free access to I-IV diets for 4 weeks. Ambient temperature was $21 \pm 3{ }^{\circ} \mathrm{C}$, humidity ranged $55 \pm 15 \%$ and illumination consisted in 12-h dark/light cycle. Free access to community tap water was allowed, except during the experiments. Blood samples were collected for the determination of the concentrations of serum cholesterol and triglycerides at the beginning and at the end of the 4-week dietary intervention. Mice were sedated with $\mathrm{CO}_{2} / \mathrm{O}_{2}$-mixture and the blood samples were collected from the orbital sinus (at the beginning) or through a cardiac puncture (at the end). At the beginning of the study the blood was collected into $500 \mu \mathrm{l}$ gel tubes and allowed to clot at least for $1 \mathrm{~h}$. Samples were then centrifuged for $15 \mathrm{~min}$ at $4000 \mathrm{rpm}$. Serum was separated and stored at $-20^{\circ} \mathrm{C}$ until analyses. At the end of the intervention, blood samples were collected in heparin tubes and centrifuged within $1 \mathrm{~h}$. The plasma samples were frozen at $-20^{\circ} \mathrm{C}$ and stored until analyses. About $50 \mu \mathrm{l}$ was used for cholesterol and triglyceride analyses and the rest was stored at $-20^{\circ} \mathrm{C}$ for further analyses. During the intervention, the animals were weighed twice a week and observed daily (morning and afternoon) for general well being.

\section{Test compounds and diets}

Plant-derived stanol ester was produced by Raisio Benecol Ltd. (Raisio, Finland). Sesamin epimer (CAS No. $607-80-7,>95 \%$ purity, Fig. 1A) was synthesized by Industrial Research Ltd. (Wellingtown, New Zealand). During acclimatization/isolation period the diet was RM1 (E) SQC, (Special Diet Service, Witham Essex, UK). Experimental atherogenic diets containing $0.25 \%$ of cholesterol were prepared at Raisio Benecol Ltd. based on Clinton-Cybulsky diet premix (D12106pxc, Research Diets Inc., New Brunswick, NJ)

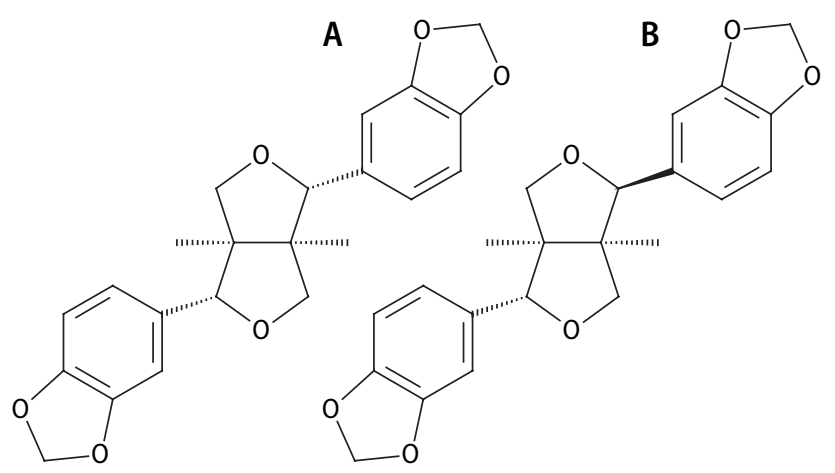

Fig. 1 Chemical structure of sesamin epimers (A) sesamin and (B) episesamin (or asarinin)

in which the test compounds were administered, as follows: control (I) diet $(n=8)$, stanol ester (II) diet $(n=8,7 \mathrm{mg} / \mathrm{kg})$, sesamin (III) diet $(n=8,1 \mathrm{mg} / \mathrm{kg})$ and combined (IV) diet $(n=7,7 \mathrm{mg} / \mathrm{kg}$ stanol ester and $1 \mathrm{mg} / \mathrm{kg}$ sesamin). Diets were stored at +2 to $+8^{\circ} \mathrm{C}$ and allowed to warm to room temperature before delivery to the animals (twice a week) in 300-ml glass cups attached on the cage floor.

\section{Rationale for dose selection}

Fat and cholesterol levels in the atherogenic diet were based on the literature [6]. The use of stanol ester as control test model has been proven several times to induce cholesterol reduction (Raisio Benecol Ltd., unpublished results) and the concentration in this study was selected to exert sufficient but not the maximal response, enabling the possible combination effect with sesamin. Sesamin concentration, that was adopted from previous reports [7-9] allowing comparison of the results was also considered as a rationale level to be used in clinical trials.

\section{Analysis}

Serum cholesterol and triglycerides were determined by Ecoline CHOD-PAP and Ecoline 25 GPO-PAP assay kits (1.14856.0001, Merck KGaA, Darmstadt, Germany), respectively. Control serum was Qualitrol HS N (Merck KGaA, Darmstadt, Germany). Serum metabolic profile of lignans was carried out by HPLC with coulometric electrode array detection [10] and the absence of plant lignans other than sesamin epimer in the diets was confirmed by isotope-dilution GC-MS [11].

\section{Statistics}

Graph Pad Prism software version 3.02 (GraphPad Software Inc., CA) was used for statistical data treat- 


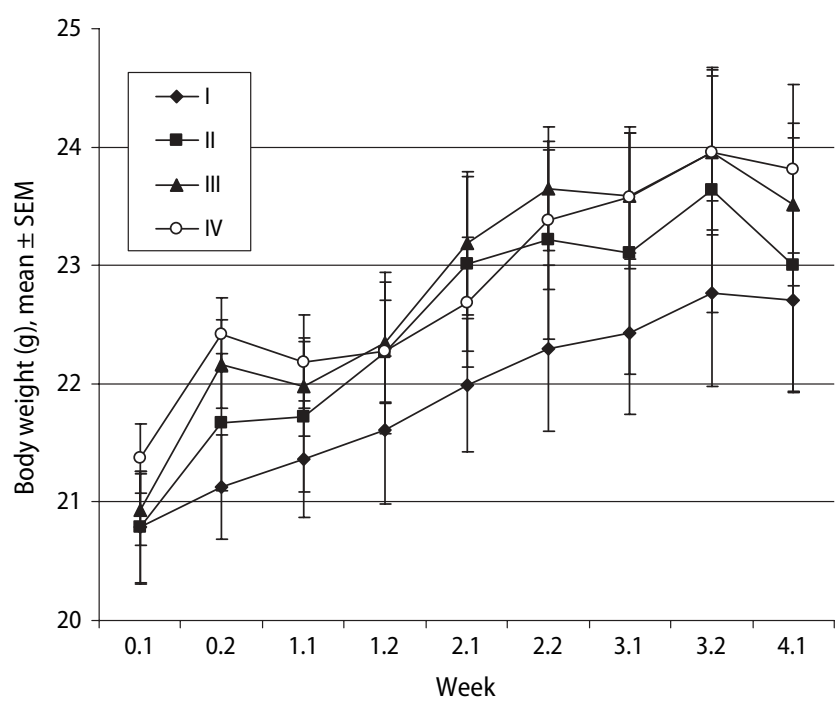

Fig. 2 Body weights of the animals in the different treatment groups during the study $(n=7-8)$

ment. The differences in changes from the basal concentrations during the intervention between the groups were analyzed by ANOVA. Pair-wise comparisons between the groups were performed by $\mathrm{Tu}-$ key's Multiple Comparison Test. Two-way ANOVA was used to analyze differences in the body weights between the groups. A P-value less than 0.05 was considered as statistically significant. All analyses were performed as two-sided tests.

\section{Results}

\section{Body weight gain}

The body weights of the animals increased in all groups during the 4-week intervention period (Fig. 2). The increment tendency in group I was less than those in the other groups but analysis did not reveal a significant group $\times$ week interaction $(P=1.00)$. However, ANOVA showed a significant group effect $(P=0.0002)$, which indicates that the body weights differed between the groups during the intervention.

\section{Effects of the atherogenic diet and test compounds on serum cholesterol and serum triglyceride concentrations}

The atherogenic diet (group I) induced an almost 3fold increase in the s-cholesterol levels but no effect was seen in the triglyceride levels. Stanol ester alone (group II) or together with sesamin (group IV) significantly attenuated the elevation of the cholesterol
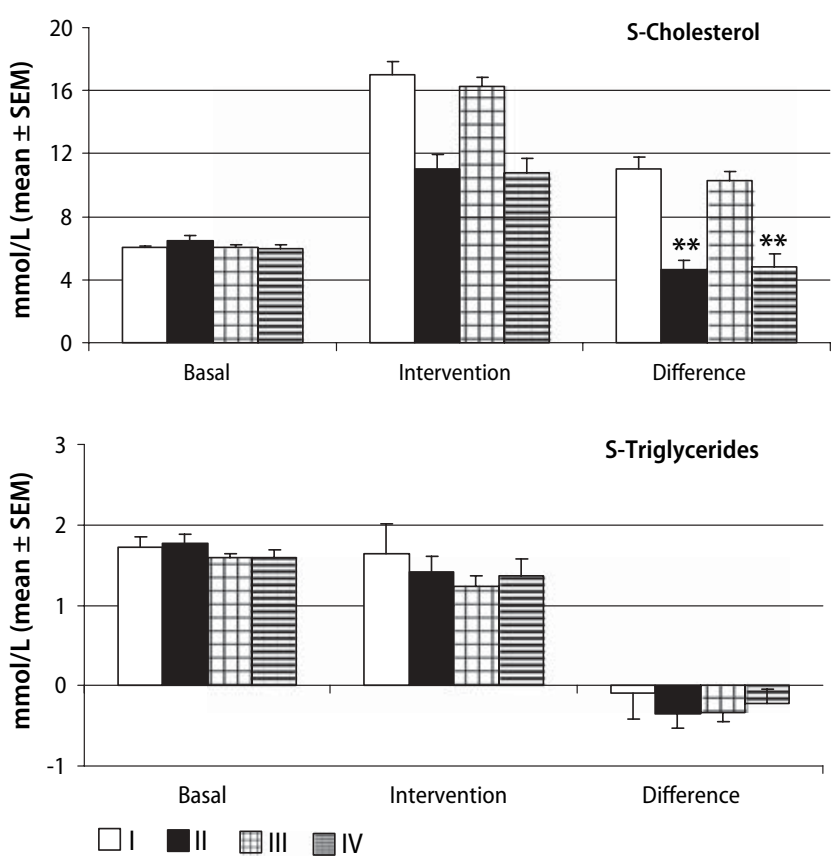

Fig. 3 S-cholesterol and -triglyceride concentrations before (Basal) and after (Intervention) the 4-week intervention with experimental diets and the difference between basal and Intervention levels (Difference). ${ }^{* *} P<0.001$ in comparison with Group 1 (Tukey's Multiple Comparison Test)

levels. Sesamin alone (group III) either normalize the elevation of cholesterol levels nor did it enhance the effect of stanol ester (group II versus group IV). Dietinduced changes in the triglyceride levels did not differ between groups $(P=0.89)$. Results are presented in Fig. 3.

\section{Effects of the atherogenic diet and test compounds on plasma lignan profile after intervention}

Presence of sesamin epimer in the diets resulted in the appearance of enterolignans in plasma, although concentrations varied greatly between animals (Table 1). Significantly increased levels of enterodiol $(P=0.00)$, but not enterolactone were found.

\section{Discussion}

As one of the major components of sesame seeds, the lignan sesamin has received a great deal of interest regarding its potential as a hypocholesterolemic agent, especially after the positive results reported by Hirata et al. [7] in humans. Thereafter, different approaches have been used to confirm this observation in which different sources of dietary sesamin have been used. Studies using sesame seed-based diets provided results that are difficult to discuss since the 
Table 1 Enterolignan (enterolactone and enterodiol) values after 4-week intervention period $\mathrm{nmol} / \mathrm{l}$ (Mean \pm SEM, $n=8$ )

\begin{tabular}{lllll}
\hline Group & $n$ & ENL $^{\text {a }}$ & END & ENL + END \\
\hline I, Control & 8 & $4.61 \pm 0.40$ & $6.11 \pm 2.10$ & $9.18 \pm 2.14$ \\
II, Stanol ester & 8 & $3.01 \pm 0.35$ & $10.0 \pm 4.69$ & $13.0 \pm 4.85$ \\
III, Sesamin & 8 & $8.01 \pm 0.98$ & $569 \pm 54.2^{* *}$ & $577 \pm 55.0^{* *}$ \\
IV, Stanol ester + sesamin & 7 & $6.54 \pm 1.99$ & $388 \pm 90.7^{* *}$ & $394 \pm 91.8^{* *}$ \\
\hline
\end{tabular}

${ }^{* *} P<0.001$ in comparison with Group 1 (Tukey's Multiple Comparison Test)

${ }^{\mathrm{a} E N L}$, Enterolactone; END, enterodiol hypocholesterolemic effect could not be primarily attributed to sesamin. As for the studies using pure sesamin supplementation, the preparations used so far contained a mixture of sesamin epimers (sesamin and episesamin in a 1:1 ratio) that they are known now to possess a different behavior both in their metabolic fate [12] and biological action [4] supporting the need to differentiate between different sesamin epimers in future studies.

A clear hypocholesterolemic effect elicited by sesamin (alone or in combination with vitamin E) was reported in studies conducted in rats $[9,13-15]$ or in cultured rat cells [16] and similarly, other biological effects proposed for sesamin [17-26], have also been studied using rats as experimental animal. Very few studies though, have used other animals than rats to test the effects of sesamin $[27,28]$. In the recent study of Kushiro et al. [3] where sesamin was tested in different experimental animals, results for rats were confirmed, but no effect was observed in hamsters or mice. Only one study has investigated the hypocholesterolemic effect of sesamin in humans [7] finding a significant effect of dietary sesamin in the reduction of total cholesterol and LDL-cholesterol. In this study however, dietary sesamin was administered together with vitamin $\mathrm{E}$ and therefore the observed effect might be due to the reported synergism between this two dietary components [14] and since no separated sesamin-group was included in the study, the hypothetical action of sesamin could not be confirmed.

In order to minimize the commented variables, in the present experiment only pure sesamin epimer was used and additionally, transgenic mice were selected for they offer the most convenient model to investigate the two proposed mechanisms for the hypocholesterolemic effect of sesamin i.e. reduction of endogenous cholesterol synthesis and reduction of dietary absorption. Due to the lack of functional LDLreceptors, the animals used in this trial have a spontaneously elevated serum cholesterol concentration, and in addition, they are prone to diet-induced modulation of the serum cholesterol concentration [5, 6]. Hepatic HMG-CoA reductase is the rate-limiting enzyme in the cholesterol biosynthetic pathway and its inhibitors are very effective in lowering plasma cholesterol. Sesamin has been reported to inhibit
HMG-CoA reductase in rats [13] and through this mechanism it has been proposed to reduce plasma cholesterol. However, in this study no reduction of serum cholesterol or triglyceride levels was observed in the group supplemented with sesamin alone (group III) and therefore it is concluded that sesamin does not affect HMG-CoA reductase in this animal model. Similarly, cholesterol supplementation $(0.25 \%$, w/w $)$ for 4 weeks increased plasma total cholesterol levels approx. 3-fold in the absence of a functional LDL receptor. However, the introduction of stanol ester in the atherogenic diet significantly reduced the total plasma cholesterol level, independently of the presence of sesamin. It is known that plant stanols inhibit the absorption of dietary cholesterol and the reabsorption (enterohepatic circulation) of endogenous cholesterol from the gastrointestinal tract [29]. It seems though that sesamin does not affect dietary cholesterol absorption in this animal model.

The metabolism of sesamin seems to play an essential role in its further biological action. It has been recently suggested that in humans, sesamin is absorbed through the portal vein reaching the liver where extensive metabolism takes places generating demethylenated (catechol) derivatives secreted as glucuronidates via the bile [26]. The same metabolites were found after in vitro fermentation of pure sesamin standard with human fecal inoculum and furthermore extensive in vivo conversion to enterolactone was reported after sesame seed supplementation in humans [11]. We hypothesized then that the absorption of sesamin could certainly take place via the portal vein and that transformation to catechol derivatives could be possible, as well as further absorption to the general circulation where they may exert the biological actions proposed for sesamin. Nevertheless, in this study as in our previous trial [11], extensive conversion of sesamin to enterolignans was observed suggesting that non-absorbed sesamin and possibly biliary catecholic sesamin derivatives undergo metabolism by gut microflora leading to the production and further absorption of enterolignans. Postprandial levels of sesamin in plasma differed considerably between rats [12] and humans [11], suggesting a different metabolic pathway depending on species. 
So far, our data suggest that a limited absorption or a too rapid enterohepatic circulation of sesamin could be the explanation for the lack of antihypercholesterolemic effect in mice/hamsters and possibly in humans but this hypothesis needs to be confirmed. Furthermore, the characteristics of our animal model did not allow to study a third mechanism for cholesterol reduction that sesamin could use; the increment of LDL-receptor activity. This hypothetical mechanism has been suggested for other dietary components [30], and it is a likely explanation of the negative results reported in this paper.

In conclusion, possible confounding factors have been minimized with the use of a specific animal model and the selection a pure sesamin epimer. It can be therefore stated that sesamin does not seem to affect cholesterol biosynthesis or absorption in mice. The so far contradictory results hinder the extrapolation to humans, and only a clinical trial with separate epimeric forms and the elucidation of the complete metabolic pathway of sesamin in humans will contribute to clarify the possible utilization of sesamin as a hyocholesterolemic agent.

Acknowledgements The authors would like to thank Mrs. Ritva Takkinen for exceptional technical assistance. Partial support was obtained from the Sigrid Jusélius Foundation, Helsinki, Finland.

\section{References}

1. Sugano M, Akimoto K (1993) Sesamin: a multifunctional gift from nature. J Chinese Nutr Soc 18:1-11

2. Namiki M (1995) The chemistry and physiological functions of sesame. Food Rev Int 11:282-329

3. Kushiro M, Takahashi K, Ide T (2004) Species differences in the physiological activity of dietary lignan (sesamin and episesamin) in affecting hepatic fatty acid metabolism. Br J Nutr 91:377-386

4. Kushiro M, Masaoka T, Hageshita S, Takahashi Y, Ide T, Sugano M (2002) Comparative effect of sesamin and episesamin on the activity and gene expresion of enzymes in fatty acid oxidation and synthesis in rat liver. J Nutr Biochem 13:289-295

5. Ishibashi S, Brown MS, Goldstein JL, Gerard RD, Hammer RE, Herz J (1993) Hypercholesterolemia in low density lipoprotein receptor knockout mice and its reversal by adenovirus-mediated gene delivery. J Clin Invest 92:883893

6. Lichtman $\mathrm{AH}$, Clinton SK, Iiyama $\mathrm{K}$, Connelly PW, Libby P, Cybulsky MI (1999) Hyperlipidemia and atherosclerotic lesion development in LDL receptor-deficient mice fed defined semipurified diets with and without cholate. Arterioscler Thromb Vasc Biol 19:1938-1944

7. Hirata F, Fujita K, Ishikura Y, Hosoda K, Ishikawa T, Nakamura H (1996) Hypocholesterolemic effect of sesame lignan in humans. Atherosclerosis 122:135-136

8. Satchithanandam S, Chanderbhan R, Kharroubi AT, Calvert RJ, Klurfeld D, Tepper SA, Kritchevsky D (1996) Effect of sesame oil on serum and liver profiles in the rat. Int $J$ Vit Nutr Res $66: 386-392$
9. Sugano M, Inoue T, Koba K, Yoshida $\mathrm{K}$, Hirose N, Shinmen Y, Akimoto K, Amachi T (1990) Influence of sesame lignans on various lipid parameters in rats. Agric Biol Chem 54:2669-2673

10. Peñalvo JL, Nurmi T, Haajanen K, AlMaharik N, Botting NP, Adlercreutz H (2004) Determination of lignans in human plasma by liquid chromatography with coulometric electrode array detection. Anal Biochem 332:384-393

11. Peñalvo JL, Heinonen S-M, Aura A-M, Adlercreutz H (2005) Dietary sesamin is converted to enterolactone in humans. J Nutr 153:1056-1062

12. Umeda-Sawada R, Ogawa M, Igarashi O (1999) The metabolism and distribution of sesame lignans (sesamin and episesamin) in rats. Lipids 34:633-637

13. Hirose $\mathrm{N}$, Inoue T, Nishihara K, Sugano M, Akimoto K, Shimizu S, Yamada H (1991) Inhibition of cholesterol absorption and synthesis in rats by sesamin. J Lipid Res 32:629-638

14. Nakabayashi A, Kitagawa Y, Suwa Y, Akimoto K, Asami S, Shimizu S, Hirose N, Sugano M, Yamada Y (1995) Alfatocopherol enhances the hypocholesterolemic action of sesamin in rats. Int J Vit Nutr Res 65:162-168

15. Kamal-Eldin A, Frank J, Razdam A, Tengblad S, Basu S, Vessby B (2000) Effects of dietary phenolic compounds on tocopherol, cholesterol, and fatty acids in rats. Lipids 35:427-435

16. Umeda-Sawada R, Fujiwara Y, Igarashi O (1994) Effect of sesamin on cholesterol synthesis and on the distribution of incorporated linoleic acid in lipid subfractions in cultured rat cells. Biosci Biotechnol Biochem 58:2114-2115
17. Gu JY, Wakizono Y, Dohi A, Nonaka M, Sugano M, Yamada K (1998) Effect of dietary fats and sesamin on the lipid metabolism and immune function of Sprague-Dawley rats. Biosci Biotechnol Biochem 62:1917-1924

18. Mizukuchi A, Umeda-Sawada R, Igarashi O (2003) Effects of dietary fat level and sesamin on the polyunsaturated fatty acid metabolism in rats. J Nutr Sci Vitaminol 49:320-326

19. Yamashita K, Nohara Y, Katayama K, Namiki M (1992) Sesame seed lignans and gamma-Tocopherol act synergistically to produce Vitamin-E activity in rats. J Nutr 122:2440-2446

20. Ikeda S, Tohyama T, Yamashita $K$ (2002) Dietary sesame seed and its lignans inhibit 2,7,8-trimethyl-2(2'carboxyethyl)-6-hydroxychroman excretion into urine of rats fed $\gamma$ tocopherol. J Nutr 132:961-966

21. Utsunomiya T, Chavali SR, Zhong WW, Forse RA (2000) Effects of sesamin-supplemented dietary fat emulsions on the ex vivo production of lipopolysaccharide-induced prostanoids and tumor necrosis factor \{alpha\} in rats. Am J Clin Nutr 72:804-808

22. Nakano D, Itoh C, Ishii F, Kawanishi H, Takaoka M, Kiso Y, Tsuruoka N, Tanaka $\mathrm{T}$ (2003) Effects of sesamin on aortic oxidative stress and endothelial dysfunction in deoxycorticosterone acetate-salt hypertensive rats. Biol Pharm Bull 26:1701-1705

23. Hirose N, Doi F, Ueki T, Akazawa K, Chijiiwa K, Sugano M, Akimoto K, Shimizu S, Yamada H (1992) Suppressive effect of sesamin against 7,12dimethylbenz[a]-anthracene induced rat mammary carcinogenesis. Anticancer Res 12:1259-1265 
24. Kamal-Eldin A, Pettersson D, Appelqvist LA (1995) Sesamin (a compound from sesame oil) increases tocopherol levels in rats fed ad libitum. Lipids 30:499-505

25. Kiso Y (2004) Antioxidative roles of sesamin, a functional lignan in sesame seed, and its effect on lipid- and alcohol-metabolism in the liver: a DNA microarray study. Biofactors 21:191196
26. Tsuruoka N, Kidokoro A, Matsumoto I, Abe K, Kiso Y (2005) Modulating effect of sesamin, a functional lignan in sesame seeds, on the transcription levels of lipid- and alcohol-metabolizing enzymes in rat liver: a DNA microarray study. Biosci Biotechnol Biochem 69:179-188

27. Akimoto K, Kitagawa $\mathrm{Y}$, Akamatsu $\mathrm{T}$, Hirose M, Sugano M, Shimizu S, Yamada H (1993) Protective effects of sesamin against liver damage caused by alcohol or carbon tetrachloride in rodents. Ann Nutr Metab 37:218-224
28. Ogawa T, Makino T, Hirose N, Sugano M (1994) Lack of influence of low blood cholesterol levels on pancreatic carcinogenesis after initiation with $N$ nitroso bis(2-oxopropyl)amine in Syrian golden hamsters. Carcinogenesis 15:1663-1666

29. Miettinen TA (2001) Cholesterol absorption inhibition: a strategy for cholesterol-lowering therapy. Int J Clin Pract 55:710-716

30. Kirk EA, Sutherland P, Wang SA, Chait A, Leboeuf RC (1998) Dietary isoflavones reduce plasma cholesterol and atherosclerosis in C57BL/6 mice but not ldl receptor-deficient mice. J Nutr 128:954-959 